\title{
The Kamuzu University of Health Sciences: a "semi" new university is born in Malawi
}

\author{
Adamson S. Muula
}

Editor-in-Chief, Malawi Medical Journal and Head of Public Health, Kamuzu University of Health Sciences (KUHeS)

Community Health Workers (CHWs) have been identified On 4th May 2021, a new university, the Kamuzu University of Health Sciences (KUHeS) started its operations in Malawi following the notice of its commencement by the Ministry of Education. ${ }^{1}$ The (semi) new university emerged from the amalgamation of two (former) constituent colleges of the University of Malawi (UNIMA), i.e. the Kamuzu College of Nursing $(\mathrm{KCN})$ and the College of Medicine (CoM). A decade ago, the University of Malawi in fact comprised some five colleges including the two mentioned above, Bunda College (of Agriculture), Chancellor College (largely for liberal arts and social sciences), and The Malawi Polytechnic (specialising in Commerce, Engineering and Applied Sciences). Following a Parliamentary decision through an Act of Parliament, Bunda College delinked from the University of Malawi in 2011 while joining with the Natural Resources College (NRC) to form the Lilongwe University of Agriculture and Natural Sciences (LUANAR). ${ }^{2}$ This year (2021), it was the turn of/for the remaining four colleges which as stated above have given birth to KUHeS, but also the Malawi University of Business and Applied Sciences (MUBAS) replacing the former Polytechnic while Chancellor College, the initial campus of the University of Malawi when it was established in 1965, has, not surprisingly and most appropriately and responsibly, retained the name of the University of Malawi (formerly, fondly referred to as the "College that God Loves Most"). Having hosted Religious Studies and Theology Departments, we only speculated how our colleagues in Zomba came to know how much the Almighty loved them.

In 1965, Chancellor College itself was a conglomeration of (its) Chichiri Campus at the former Sir Robert Armitage High School, Soche College of Education and Mpemba Staff Development Institute. In 1972, Chancellor College moved from Blantyre to its permanently place at Chirunga in Zomba. ${ }^{3}$ On the other hand the decision to create the College of Medicine was made in 1986 by former Head of State Dr Hastings Kamuzu Banda. ${ }^{4}$ That was 7 years in fact after the creation of the Kamuzu College of Nursing, which itself had emerged from the Blantyre (National) School on Nursing in 1979. In either case, the creation of both CoM and KCN was deliberate, cautious and sequential. With $\mathrm{KCN}$, Ms Margaret Page was hired as its first principal, and the highest academic qualifications students could attain then was a three-year university diploma. After the threeyear diploma, all graduates were required to also complete a one-year university certificate in midwifery. Although the intake of men into KCN was possible, only a handful of men were initially admitted. There has never been a male principal for this prestigious nursing and midwifery college.
In the case of the College of Medicine, when the decision to open a medical school was made in 1986, the government opined that it was not possible to start with a fully-fledged medical school. A decision was therefore made to send several cohorts of students to Scotland, thereafter England, Australia and South Africa, to allow them attend Basic Medical Sciences tuition and be introduced to early clinical sciences before they could return back home, at which point some components of clinical instruction would have been set in place. ${ }^{4-6}$ The first Principal and Executive Dean was Prof Geoffrey Dahlenberg, an Australian Paediatrician who had previously served as Dean of the Medical School at the University of Adelaide, while Dr John David Chiphangwi was Director of Studies and Manager of the Medical School Project in the Ministry of Health. What was then Ministry of Health's Medical School Project building at Limbe now hosts a motor vehicle spare parts and other retail shops!

The CoM started with the MBBS (Bachelor of Medicine and Bachelor of Surgery) Program. This was intentional as it was perceived to be the greatest need at the time. There was urgency to establish the leadership in clinical sciences first before other allied disciplines were created. It was therefore the case that degrees in pharmacy, medical laboratory technology (later medical laboratory sciences) and physiotherapy came in much later. As of 2021, overall student undergraduate intake had achieved gender parity while for postgraduate students, more women are admitted than men. Contrasted with the KCN which had never had a male principal or vice principal, the College of Medicine had never had a female principal nor vice principal. The coming in of KUHEs therefore should be exciting as two institutions both with limited experience of gender inclusiveness at their top administrative levels must navigate what it is to be a responsive institution in the 21 st century. The desire to be responsibly represented at all levels of the establishment should receive the much needed attention. And this should not just be in administrative realm but also in academic leadership sense. The KCN has never had a male professor, currently the CoM has no female professor. Now $\mathrm{KUHeS}$ has two female professors, all having come from the KCN. While students at the CoM had been used to a context where their numbers had achieved gender balance but their professors were largely male, now they have to learn what it is like when the faculty is somewhat balanced but there are more female students than are males. The new university (not just a college) becomes the first public university in Malawi where males shall be in minority by far. We will be competing squarely with the Scandinavians and perhaps Rwanda, shoulder to shoulder. Denmark, Sweden and Norway, you are far much behind than KUHeS! 
In future, the Malawi Medical Journal should invite authors to write on the potential pros and cons of the amalgamation of the College of Medicine and Kamuzu College of Nursing to become one university. It is not that such write-ups aren't already available, but rather not accessible to many readers of the Journal. And as we implement this exciting project (KUHeS), intermittent or paroxysmal assessments and chronicling of the experience will be worth the pages of the Journal. Readers would now wish to be reminded that these pages (the Malawi Medical Journal) are a joint publication of the College of Medicine and the Medical Association of Malawi (MAM). We, at the journal will soon be having discussions with our board and the owners as to what we shall become, if at all we should become anything else other than the Malawi Medical Journal. Do we become a health sciences journal or we continue to be a medical journal, for instance? Currently, we understand ourselves to be a general medical journal. We are not a specialist journal and neither are we not a medical journal. We should also be open to facilitate the creation of the Malawi Journal of Nursing or the Journal of Midwifery in Malawi, should colleagues in the Nursing and Midwifery disciplines be desirous of such. Personally, I am proud to go down in history as the Editor-in-Chief of the Malawi Medical Journal who served as the last when the (Malawi) College of Medicine existed, and the first when $\mathrm{KuHeS}$ became into being. One thing is certain, at least for me, i.e. to continue serving and servicing medical authors and readers as the board and the owner shall wish. As a journal, we (presently) remain indexed in MEDLINE and other databases of note in medical journal publishing, and we continue to be ranked as one of the prestigious medical journals on the African continent. What a privilege I have!

\section{Acknowledgements}

The Malawi Medical Journal (MMJ) is a member of the African Journal Partnership Programme (https://www.fic.nih.gov/ About/center-global-health-studies/Pages/african-journalpartnership-project-ajpp.aspx) whose founding members in 2004 also included the National Library of Medicine and Fogarty. The Partnership Programme receives support from the National Library of Medicine (NLM) and Council of Science Editors.

\section{References}

1. Gazette Extraordinary. University of Kamuzu University of Health Sciences (No. 20 of 2019). Notice of Commencement, Government Printer, Lilongwe, Malawi

2. Malawi Government Gazette. Lilongwe University of Agriculture and Natural Resources (Act of Parliament 22 of 2011), Government Printer, Lilongwe, Malawi

3. Michael, I. Academic autonomy and governmental demands: The case of Malawi. Minerva 16, 465-479 (1978). https://doi.org/10.1007/ BF01100329

4. Muula AS, Broadhead RL. The first decade of the Malawi College of Medicine: a critical appraisal. Trop Med Int Health. 2001 Feb;6(2):1559. doi: 10.1046/j.1365-3156.2001.00673.x.

5. Muula AS, Broadhead RL. South Africa's role in medical training in Malawi. S Afr Med J. 2003 Feb;93(2):119-20.

6. Muula AS, Broadhead RL. The Australian contribution towards medical training in Malawi. Med J Aust. 2001 Jul 2;175(1):42-7. doi: 10.5694/j.1326-5377.2001.tb143513.x. 